\title{
Solution to bisphenol A measurement challenge
}

\section{Enea Pagliano ${ }^{1}$}

Accepted: 25 October 2021 / Published online: 12 January 2022

(C) Crown copyright in right of Canada 2022

The winner of the Bisphenol A measurement challenge (published in volume 413 issue 16) is: Charles Lucy, University of Alberta, Edmonton, AB, Canada T6G $2 G 2$.

The award entitles the winner to select a Springer book of his choice up to a value of 100,--

\section{Our Congratulations!}

In the Bisphenol A measurement challenge [1], Prof. Phenole proposed to her class to develop a high-precision analytical procedure for the determination of bisphenol A in water. The students promptly embraced the challenge and developed an isotope dilution gas chromatography mass spectrometry (ID GC-MS) method using the isotopically labeled ${ }^{13} \mathrm{C}_{5}$-BPA internal standard [2]. The students did all due diligence to set up the method but, during the quality control check, they found a $-8.0 \%$ bias at the low-end of the calibration curve.

When looking for a possible explanation, the students came across two interesting studies: in 1976 Pickup and McPherson showed that the isotope dilution mass spectrometry (IDMS) calibration curve can be nonlinear [3], and in 2016 Raposo noted that the coefficient of determination $\left(R^{2}\right)$ is not at all suitable to establish whether a calibration curve is linear or not [4].

With this information at hand, the students decided to spend some time investigating the linearity of their calibration curve. As expected, the graph of the residuals showed a trend typical of a nonlinear response (Fig. 1) [5].

The students with a theoretical background were reassured by this finding and were confident that this was a data analysis problem with no additional experiments needed. They decided to use a nonlinear mathematical model for the calibration curve. At first, they used a generic quadratic function of the

This article is the solution to the Analytical Challenge to be found at https://doi.org/10.1007/s00216-021-03383-8.

Enea Pagliano

enea.pagliano@nrc-cnrc.gc.ca

1 National Research Council Canada, 1200 Montreal Road, K1A 0R6, Ottawa, Ontario, Canada form $y=a_{0}+a_{1} \cdot x+a_{2} \cdot x^{2}$. When the quadratic model was applied to the data in Table 1, the fitting coefficients were calculated using the ordinary least squares (OLS), as reported in Table 2. The quadratic function was reasonably adequate to account for the nonlinear effects, also in the low end of the calibration. Since the adoption of the quadratic model was not motivated by any theoretical reason, the students decided to further investigate the origin of the nonlinear trend. Using some algebra, the general isotope dilution equation could be reworked into the following expression [6]:

$y=\frac{a_{0}+a_{1} \cdot x}{1+a_{2} \cdot x}$
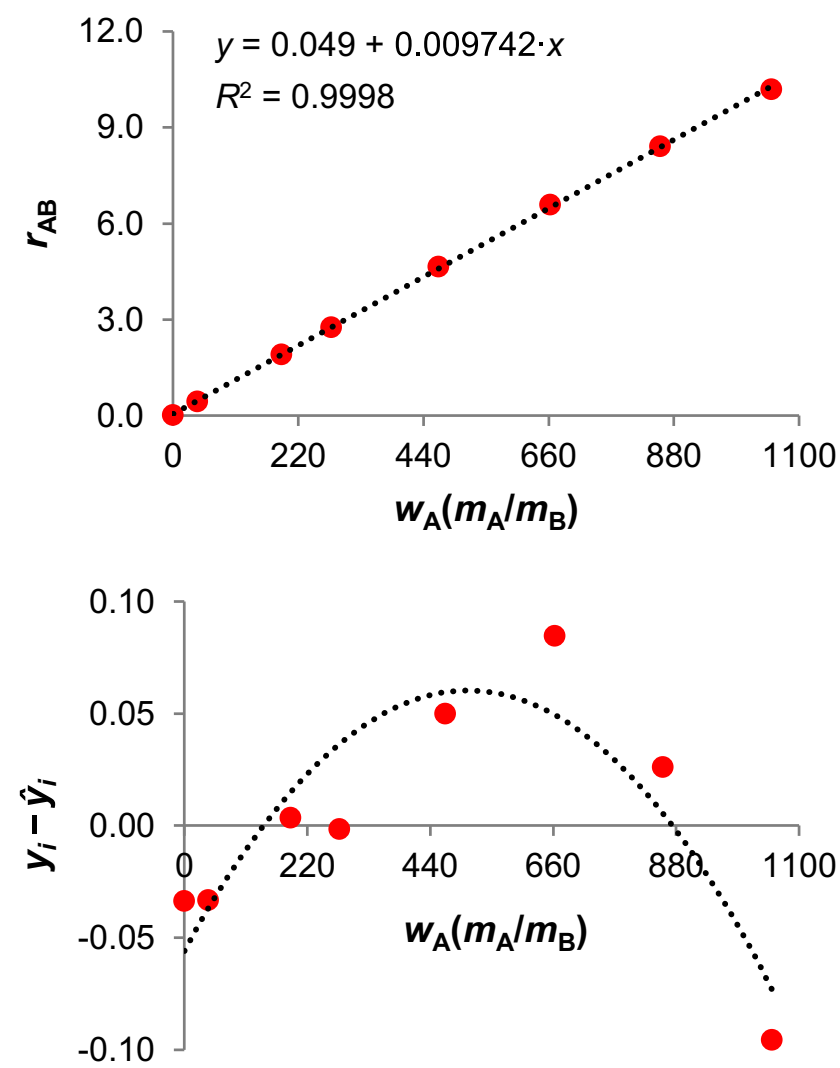

Fig. 1 Top: isotope dilution calibration curve of BPA with ${ }^{13} \mathrm{C}_{5}$-BPA internal standard from Ref. [1]. Bottom: graph of the residuals 
Table 1 Isotope dilution with ${ }^{13} \mathrm{C}_{5}$-BPA internal standard: calibration curve and errors using linear, quadratic and rational model equations

\begin{tabular}{|c|c|c|c|c|c|c|c|c|c|c|}
\hline \multicolumn{5}{|c|}{ Experimental data } & \multicolumn{2}{|c|}{ Linear model } & \multicolumn{2}{|c|}{ Quadratic model } & \multicolumn{2}{|c|}{ Rational model } \\
\hline$w_{\mathrm{A}}$ & $m_{\mathrm{A}}$ & $m_{\mathrm{B}}$ & $w_{\mathrm{A}}\left(m_{\mathrm{A}} / m_{\mathrm{B}}\right)$ & $r_{\mathrm{AB}}$ & $\hat{w}_{\mathrm{A}}$ & Error & $\hat{w}_{\mathrm{A}}$ & Error & $\hat{w}_{\mathrm{A}}$ & Error \\
\hline $\mathrm{ng} / \mathrm{g}$ & $\mathrm{g}$ & $\mathrm{g}$ & $\mathrm{ng} / \mathrm{g}$ & $\mathrm{V} / \mathrm{V}$ & $\mathrm{ng} / \mathrm{g}$ & $\%$ & $\mathrm{ng} / \mathrm{g}$ & $\%$ & $\mathrm{ng} / \mathrm{g}$ & $\%$ \\
\hline 0.000 & 0.8867 & 0.3844 & 0.000 & $0.0149(23)$ & & & & & & \\
\hline 19.66 & 0.8693 & 0.3978 & 42.96 & $0.4338(42)$ & 18.10 & $-8.0 \%$ & 19.83 & $0.9 \%$ & 19.83 & $0.8 \%$ \\
\hline 85.80 & 0.8835 & 0.3981 & 190.4 & $1.907(18)$ & 85.96 & $0.2 \%$ & 85.29 & $-0.6 \%$ & 85.26 & $-0.6 \%$ \\
\hline 126.7 & 0.8693 & 0.3965 & 277.8 & $2.753(32)$ & 126.6 & $-0.1 \%$ & 125.0 & $-1.4 \%$ & 124.9 & $-1.4 \%$ \\
\hline 210.5 & 0.8789 & 0.3965 & 466.6 & $4.644(60)$ & 212.8 & $1.1 \%$ & 210.1 & $-0.2 \%$ & 210.1 & $-0.2 \%$ \\
\hline 304.5 & 0.8629 & 0.3963 & 663.0 & $6.592(75)$ & 308.5 & $1.3 \%$ & 306.2 & $0.6 \%$ & 306.2 & $0.6 \%$ \\
\hline 392.5 & 0.8662 & 0.3971 & 856.2 & $8.415(39)$ & 393.7 & $0.3 \%$ & 393.5 & $0.3 \%$ & 393.5 & $0.3 \%$ \\
\hline 477.4 & 0.8693 & 0.3948 & 1051 & $10.193(33)$ & 472.9 & $-0.9 \%$ & 476.3 & $-0.2 \%$ & 476.2 & $-0.2 \%$ \\
\hline
\end{tabular}

The standard deviation of triplicate measurements (applicable to the last two digits of the value) is given in the parentheses. $w_{\mathrm{A}}$, mass fraction of natural BPA; $m_{\mathrm{A}}$, mass of the solution having $w_{\mathrm{A}}$ mass fraction; $m_{\mathrm{B}}$, mass of the internal standard solution having $w_{\mathrm{B}}=94.4 \mathrm{ng} / \mathrm{g} ; w_{\mathrm{A}}\left(m_{\mathrm{A}} / m_{\mathrm{B}}\right)$ $=$ corrected mass fraction $\left(x\right.$-axis); $r_{\mathrm{AB}}=$ measured isotope ratio of the blend ( $y$-axis). The error associated to the model was calculated as the relative difference between the mass fraction predicted using the model $\left(\hat{w}_{\mathrm{A}}\right)$ and the gravimetric one $\left(w_{\mathrm{A}}\right):\left(\hat{w}_{\mathrm{A}}-w_{\mathrm{A}}\right) / w_{\mathrm{A}}$

where $y$ is the isotope ratio $\left(r_{\mathrm{AB}}\right)$ and $x$ is the mass fraction corrected by the gravimetric composition of the blends $\left(w_{\mathrm{A}}\right.$. $\left.m_{\mathrm{A}} / m_{\mathrm{B}}\right)$. Since Eq. 1 was obtained from first principles, the theoreticians tried fitting it to the isotope dilution data. As shown in Table 1, the performance of both quadratic and rational model were similar with relative errors $<1.5$ $\%$ across the calibration range-well within the target requested by Prof. Phenole.

Although the theoreticians were satisfied about the results obtained, another group of students was more resistant to take all this mathematics and decided to go back to the laboratory and find a suitable practical solution that could tolerate the use of a linear model. This is possible because in IDMS the level of nonlinearity can be tuned by changing the experimental conditions [7]. For example, the linearity improves when the amount of internal standard increases. With this in mind, the experimental folks returned to the laboratory and decided to use 5.4 times more internal standard. Just to be sure, they also reduced the dynamic range and increased the number of working standards. Under these conditions, they observed that the linear model could be used to build the calibration curve with good performance even at low concentration: with an error $<1 \%$-the solution proposed by the experimentalists exceeded the expectation of Prof. Phenole (Table 3).

Prof. Phenole was impressed by both approaches. Although the students did not provide a full bottom-up evaluation of uncertainty [8], which should have been done to properly qualify the method, Prof. Phenole was delighted to see the students' commitment to deal with nonlinear issues in isotope dilution and full marks were awarded to the class.

Notably, the theoreticians reveled that when the isotopes of the analyte overlap with those of the internal standard (which happens almost all the time) the IDMS response is always nonlinear, and, therefore, a nonlinear model should be used for calibration [6]. On the other hand, the experimentalists sidestepped the nonlinearity issue by adopting better experimental conditions aimed to minimize the nonlinear

Table 2 Mathematical models for the interpretation of the isotope dilution calibration curve in Table 1

\begin{tabular}{|c|c|c|c|c|}
\hline Model equation & $a_{0}$ & $a_{1}$ & $a_{2}$ & Excel code \\
\hline \multirow[t]{2}{*}{$y=a_{0}+a_{1} \cdot x$} & 0.049 & 0.009742 & & \multirow[t]{2}{*}{$=\operatorname{LINEST}(y, x$, TRUE,TRUE) } \\
\hline & 0.034 & 0.000059 & & \\
\hline \multirow[t]{2}{*}{$y=a_{0}+a_{1} \cdot x+a_{2} \cdot x^{2}$} & -0.007 & 0.01020 & $-4.51 \cdot 10^{-7}$ & \multirow[t]{2}{*}{$=\operatorname{LINEST}\left(y, x^{\wedge}\{1,2\}\right.$, TRUE,TRUE) } \\
\hline & 0.021 & 0.00011 & $1.01 \cdot 10^{-7}$ & \\
\hline \multirow[t]{2}{*}{$y=\left(a_{0}+a_{1} \cdot x\right) /\left(1+a_{2} \cdot x\right)$} & -0.008 & 0.01021 & $4.71 \cdot 10^{-5}$ & \multirow[t]{2}{*}{$=\operatorname{LINEST}\left(y, x^{\wedge}\{1,1\}^{*}-y^{\wedge}\{0,1\}, \mathrm{TRUE}, \mathrm{TRUE}\right)$} \\
\hline & 0.022 & 0.00012 & $1.12 \cdot 10^{-5}$ & \\
\hline
\end{tabular}

Microsoft Excel 2013 was used to perform the ordinary least squares fitting with the LINEST function. The value of the fitting parameters is reported on the first line whereas the standard uncertainty is reported in italic on the second line. Here, $y$ is the isotope ratio $\left(r_{\mathrm{AB}}\right)$ and $x$ is the analyte mass fraction normalized by the gravimetric composition $\left(w_{\mathrm{A}} \cdot m_{\mathrm{A}} / m_{\mathrm{B}}\right)$ 
Table 3 Isotope dilution with ${ }^{13} \mathrm{C}_{5}$-BPA internal standard: more internal standard, more calibration data, and shorter dynamic range

\begin{tabular}{|c|c|c|c|c|c|c|}
\hline \multicolumn{5}{|c|}{ Experimental data } & \multicolumn{2}{|c|}{ Linear function } \\
\hline$w_{\mathrm{A}}$ & $m_{\mathrm{A}}$ & $m_{\mathrm{B}}$ & $w_{\mathrm{A}}\left(m_{\mathrm{A}} / m_{\mathrm{B}}\right)$ & $r_{\mathrm{AB}}$ & $\hat{w}_{\mathrm{A}}$ & Error \\
\hline $\mathrm{ng} / \mathrm{g}$ & $\mathrm{g}$ & $\mathrm{g}$ & $\mathrm{ng} / \mathrm{g}$ & $\mathrm{V} / \mathrm{V}$ & $\mathrm{ng} / \mathrm{g}$ & $\%$ \\
\hline 0.000 & 0.8723 & 0.3857 & 0.000 & 0.00098 & & \\
\hline 44.41 & 0.8555 & 0.3867 & 98.24 & $0.18877(56)$ & 44.73 & $0.7 \%$ \\
\hline 92.01 & 0.8687 & 0.3941 & 202.8 & $0.3888(31)$ & 92.60 & $0.6 \%$ \\
\hline 131.9 & 0.8760 & 0.3892 & 296.9 & $0.5675(20)$ & 132.4 & $0.4 \%$ \\
\hline 180.7 & 0.8655 & 0.3902 & 400.8 & $0.76696(92)$ & 181.6 & $0.5 \%$ \\
\hline 225.2 & 0.8735 & 0.3888 & 505.9 & $0.959(12)$ & 224.3 & $-0.4 \%$ \\
\hline 275.8 & 0.8622 & 0.3909 & 608.3 & $1.159(10)$ & 276.1 & $0.1 \%$ \\
\hline 317.1 & 0.8661 & 0.3893 & 705.5 & $1.3308(65)$ & 314.3 & $-0.9 \%$ \\
\hline 363.4 & 0.8677 & 0.3920 & 804.3 & $1.518(19)$ & 360.4 & $-0.8 \%$ \\
\hline 457.9 & 0.8636 & 0.3915 & 1010 & $1.9386(65)$ & 461.9 & $0.9 \%$ \\
\hline
\end{tabular}

The absolute difference of duplicate measurements (applicable to the last two digits of the value) is given in the parentheses. All other conventions are the same as reported in Table 1 with the expectation of $w_{\mathrm{B}}=512.0 \mathrm{ng} / \mathrm{g}$

deviations [7]; this way, the linear model could still be considered a viable option for IDMS calibration.

Before dismissing the class, Prof. Phenole commented that measurements in bioanalytical chemistry always benefit from the synergy between a well designed measurement methods and proper data analysis approaches.

\section{Declarations}

Conflict of interest The author declares no competing interests.

\section{References}

1. Pagliano E. Bisphenol a measurement challenge. Anal Bioanal Chem. 2021;413(16):4105-4107. https://doi.org/10.1007/s00216021-03383-8.

2. Le PM, Bates J, Meija J, Pagliano E, Mester Z, Melanson J. BPAL-1: Certified reference material of [13C5]-bisphenol A: National Research Council Canada, Ottawa. Available from: https://doi.org/10.4224/crm.2017.bpal-1.
3. Pickup JF, McPherson K. Theoretical considerations in stable isotope dilution mass spectrometry for organic analysis. Anal Chem. 1976;48(13):1885-1890. https://doi.org/10.1021/ac50007a 019.

4. Raposo F. Evaluation of analytical calibration based on leastsquares linear regression for instrumental techniques. A Tutor Rev Trends Anal Chem. 2016;77:167-185. https://doi.org/10.1016/j. trac.2015.12.006.

5. Ellison SLR, Barwick VJ, Farrant TJD. Practical statistics for the analytical scientist, a bench guide, 2nd Edn. UK: RSC Publishing; 2009.

6. Pagliano E, Mester Z, Meija J. Calibration graphs in isotope dilution mass spectrometry. Anal Chim Acta. 2015;896:63-67. https://doi.org/10.1016/j.aca.2015.09.020.

7. Pagliano E, Meija J. A tool to evaluate nonlinearity in calibration curves involving isotopic internal standards in mass spectrometry. Int J Mass Spectrom. 2021;464:116557. https://doi.org/10.1016/j. ijms.2021.116557.

8. JCGM 100. Evaluation of measurement data - Guide to the expression of uncertainty in measurement. 2008.

Publisher's note Springer Nature remains neutral with regard to jurisdictional claims in published maps and institutional affiliations. 